\title{
Personal and Social Responsibility Among Athletes: the Role of Self-Determination, Achievement Goals and Engagement
}

\author{
by \\ Paulo Martins ${ }^{1}$, António Rosado', Vítor Ferreira ${ }^{1}$, Rui Biscaia ${ }^{2}$
}

\begin{abstract}
The purpose of this study was to assess the relationship between motivation, engagement and personal and social responsibility among athletes. Based on the literature, a survey was conducted including measures of motivation, considering task orientation and ego orientation, intrinsic and extrinsic motivation, and amotivation. We also measured the components of engagement (dedication, confidence, vigor and enthusiasm) and the components of personal and social responsibility. A total of 517 athletes from different types of sports participated in the study. The results gathered through a structural equation model revealed that task orientation had the strongest relationship with personal responsibility and social responsibility, followed by engagement. Self-determination levels were not associated with personal and social responsibility. These results suggest that monitoring of task orientation and engagement levels should be performed by coaches as a strategy to develop personal and social responsibility among their athletes. Moreover, findings from this study provide scholars with a tool to aid them in managing athletes' levels of personal and social responsibility.
\end{abstract}

Key words: psychology, sport, athletes, motivation.

\section{Introduction}

In sport, training of life skills can be used in a variety of contexts, reducing negative behaviors and promoting positive youth development (Danish et al., 2004). Sport can promote positive youth development as it is organized, requires effort over time, and includes interpersonal relationships with adults (Lerner, 2009). Hence, from a scholastic perspective, sport constitutes a key strategy in promoting both personal and social responsibility, resulting in positive social behaviors among youngsters (Hellison and Martineck, 2006; Hellison and Walsh, 2002). Personal and social responsibility (PSR) is a form of positive development to prepare youth for life, where the development of skills, values and virtues will provide a successful transition to adulthood (Escartí et al., 2010;

Hellison and Martineck, 2006). Given the specific
features of sport (e.g., ethical and cultural
elements), there is also a strong chance that the
development and retention of personal and social
positive behaviors could be optimized by
encouraging long lasting sport participation
(Escartí et al., 2013; Wright and Li, 2009).
However, the potential impact of non-mandatory
activities (such as sport) relies on people freely
deciding to start and, afterwards, continue taking
part in them (Watson et al., 2003). This highlights
the need to study the effect of athletes'
motivations to participate in sport, and how they
relate to personal and social responsibility levels
(Catalano et al., 1999; Wright and Craig, 2011).
According to Ward and Parker (2012), the positive
development of young people is greatly

1 - Faculdade de Motricidade Humana, Universidade de Lisboa, Portugal.

2 - Coventry University, United Kingdom. 
influenced by the self-determination levels, which has the potential to provide a basic structure to programs for youth development. Selfdetermination consists of being driven by a high level of intrinsic motivation and commitment when freely choosing to take part in an activity. This means being driven by the mere pleasure and satisfaction of taking part in an activity (Deci and Ryan, 2000; Vallerand and Thill, 1993). According to Vallerand and Fortier (2001), extrinsically motivated individuals (e.g., athletes) engage in the activity to achieve an outcome, in the form of an advantage or reward. In addition, Deci and Ryan (2000) highlight that the measurement of 'amotivation' may prove to be helpful when studying persistence in sport and physical activities. Based on previous literature, one may argue that 'intrinsic motivation', 'extrinsic motivation' and 'amotivation' might represent important dimensions of a motivational construct relevant in achieving a better understanding of the development of personal and social responsibility (Carbonneau et al., 2012).

On the other hand, some studies have suggested that achievement-oriented motivation plays a pivotal role in predicting cognitions, affections, and behaviors (Nichols, 1989) within achievement-oriented scenarios (such as sport). According to the achievement goal theory proposed by Nichols (1989), athletes' motivation to engage in sport practices is driven by success oriented goals and an achievement centered attitude. This highlights the importance of both task and ego goal perspectives in measuring motivation in sports (Duda and Hall, 2001). Task orientation is an indicator of strong sport involvement, while also being connected to positive attitudes and social behaviors (Biddle and Mutrie, 2001). In turn, ego orientation entails the comparison of one's performance to that of others (Duda and White, 1992). An extensive number of programs geared towards promoting the development of socially oriented personal responsibility have shown that task orientation mind-sets constitute a good predictor of positive social attitudes, whereas ego orientation motivation is strongly connected with negative social attitudes (Lee et al., 2000).

Klem and Connell (2004) argued that there was empirical support linking engagement to both achievement and positive behavior.
Engagement is a psychological construct that describes the 'energy in action', in the form of the link between a person and an activity (Russel et al., 2005). It offers robust information over time, thereby facilitating possible interventions during the course of sport participation (Appleton et al., 2008). Given that positive environments facilitate the development of positive behaviors, engagement is considered to have positive effects on the type of involvement and cognition during sport practice (Lonsdale et al., 2007).

Although different levels of motivation (in both intensity and orientation) and engagement have been connected with the development of positive social competences (Biddle et al., 2003; Duda and Hall, 2001), most studies have failed to include these aspects simultaneously when assessing personal and social responsibility (Wright and Craig, 2011). This gap is certainly evident in the sport setting, given that the existing studies are mainly theoretically-driven and do not provide empirical results for understanding how personal and social responsibility are achieved among athletes (Hellison and Martineck, 2006). Therefore, motivation and engagement constructs should be included in studies focused on the development of personal and social responsibility. Thus, the purpose of this study was to examine the relationship between self-determination and achievement goal motivation, engagement as well as personal and social responsibility among athletes.

\section{Material and Methods}

\section{Participants}

Participants were selected from different (a) competitive levels (i.e. elite, national and regional levels), (b) sports [i.e. team sports $(n=313 ; 60.5 \%)$, individual sports $(\mathrm{n}=133 ; 25.7 \%)$ and combat sports $(\mathrm{n}=71 ; 13.7 \%)]$, and (c) regions of Portugal. Males $(n=365)$ represented about two thirds of the sample $(77.3 \%)$, and the mean age was 16.97 years $(S D=4.51)$. The sample exceeded the minimum sample size $(n=200)$ recommended for structural equation modelling (Hair et al., 2009).

\section{Measures}

The personal and social responsibility scale (PSR) consisted of two sub-scales derived from $\mathrm{Li}$ et al. (2008) and Martins et al. (2015). The construct of personal responsibility (four items) 
reflected effort and self-direction, with sample items being comprised of "I try hard" and "I set goals for myself". Secondly, the construct of social responsibility (four items) reflected respect for others and caring for others, with sample items being comprised of "I respect others" and "I am helpful to others". These items were measured using a 6-point Likert-type scale, ranging from 1 (strongly disagree) to 6 (strongly agree). The engagement scale included the constructs of confidence (four items), dedication (four items), vigor (four items) and enthusiasm (four items), which were derived from the studies of Lonsdale et al. (2007) and Martins et al. (2014). Sample items included for example: 'I believe I am capable of accomplishing my goals in sport' (confidence); 'I am determined to achieve my goals in sport' (dedication); 'I feel excited about my sport' (enthusiasm); and 'I feel really alive when I participate in my sport' (vigor). Athletes were asked to indicate how they felt engaged through a 5-point Likert-type scale, ranging from 1 (strongly disagree) to 5 (strongly agree).

To assess the dimension of athletes' motivation, a total of 28 items derived from the Sport Motivation Scale (Pelletier et al., 1995), adapted to the Portuguese context by Serpa et al. (2004), were used. Athletes were asked to indicate 'to what extent each of the items corresponds to one of the reasons for which they are presently practicing their sport'. The items were measured on a 7-point Likert-type scale, ranging from 'Does not correspond at all' (1) to 'Corresponds exactly'. Sample items included for example: 'For the pleasure it gives me to know more about the sport that I practice' (Intrinsic motivation to know - four items); 'Because I feel a lot of personal satisfaction while mastering certain difficult training techniques' (Intrinsic motivation to accomplish four items); 'For the pleasure I feel in living exciting experiences' (Intrinsic motivation to experience stimulation - four items); 'Because, in my opinion, it is one of the best ways to meet people' (Extrinsic motivation identified - four items); 'Because it is absolutely necessary to do sports if one wants to be in shape' (Extrinsic motivation introjected - four items); 'For the prestige of being an athlete' (Extrinsic motivation external regulation - four items); 'It is not clear to me anymore; I don't really think my place is in sport' (Amotivation - four items). All these items were measured on a 7-point Likert-type scale, ranging from 1 (Does not correspond at all) to 7 (Corresponds exactly). The task and ego orientation constructs were measured through the thirteen items of the Task and Ego Orientation in Sport Questionnaire, used by $\mathrm{Chi}$ and Duda (1995) and Fonseca and Biddle (2001): task orientation (six items) and ego orientation (seven items). The subjects were asked to think about the time when they felt most successful in the sport in which they competed. Sample items included for example: 'I am the only one who can perform the play or skill' (Ego orientation - six items); 'I learn a new skill and it makes me want to practice more' (Task orientation - seven items). These items were measured on a 5-point Likert-type scale, ranging from 1 (strongly disagree) to 5 (strongly agree).

\section{Procedures}

Athletes were invited to participate voluntarily in the study, and received no incentives. Before responding to the questionnaires, information about the purpose, goals and methods of the study was provided to all participants. Each athlete (or their parents when appropriate) gave their approval by filling out a consent form for inclusion in the study. A total of 600 questionnaires were distributed before the training sessions. The questionnaires were selfadministered and completion took approximately 15 minutes. After data screening, a total of 517 questionnaires were deemed usable for data analyses.

\section{Statistical Analysis}

A two-step maximum likelihood structural equation model procedure was performed using AMOS 21.0. Firstly, a confirmatory factor analysis (CFA) was conducted to examine the psychometric properties of the model. Internal consistency of the constructs was assessed through composite reliability (Hair et al., 2009), while average variance extracted (AVE) values were estimated to assess convergent validity. Discriminant validity was established when the correlation coefficients were lower than the suggested criterion of .85 (Kline, 2005) and when the AVE for each construct exceeded the squared correlations between that construct and any other (Fornell and Larcker, 1981). Secondly, a structural model was performed to test the proposed relationships between the constructs. The 
appropriateness of both the measurement and structural model was examined using the ratio of chi-square to its degrees of freedom $\left(\chi^{2} / \mathrm{df}\right)$, comparative-of-fix index (CFI), Tucker-Lewis index (TLI), and root mean square error of approximation (RMSEA). The significance of the structural weights was evaluated using the $Z$ tests produced by AMOS and statistical significance was assumed at a .05 level.

\section{Results}

\section{Analysis of the measurement model}

The skewness values for the items used in this study ranged from -1.37 to 1.70 , while the kurtosis values ranged from -.35 to 5.76 . According to Kline (2005), these values did not represent nonnormality problems and could be used in factor analysis. The results of the CFA showed that the measurement model demonstrated good fit to the data $\left[\chi^{2}(1380)=2632.36,(p<.001), \chi^{2} / d f=1.91\right.$, CFI $=.91, \mathrm{TLI}=.90$, RMSEA $=.04]$. The $\chi^{2}$ value was significant and its ratio to the degrees of freedom was below the threshold of 3.0 (Kline, 2005).

Table 1

Factor loadings, Z-values, construct reliability (CR), and average variance extracted $(A V E)$

\begin{tabular}{|c|c|c|c|c|}
\hline Constructs/items & $\begin{array}{l}\text { Factor } \\
\text { Loading }\end{array}$ & $\begin{array}{c}\text { Z- } \\
\text { value }\end{array}$ & CR & AVE \\
\hline Personal Responsibility & & & .80 & .50 \\
\hline I respect others & .67 & 16.215 & & \\
\hline I help others & .76 & 18.563 & & \\
\hline I encourage others & .70 & 17.355 & & \\
\hline I am kind to others & .69 & 16.209 & & \\
\hline Social Responsibility & & & .83 & .55 \\
\hline I try hard & .81 & 20.839 & & \\
\hline I set goals for myself & .66 & 15.436 & & \\
\hline I want to improve & .67 & 15.775 & & \\
\hline I give a good effort & .87 & 22.753 & & \\
\hline Confidence & & & .89 & .68 \\
\hline I believe I am capable of accomplishing my goals in sport & .78 & 20.612 & & \\
\hline I feel capable of success in my sport & .89 & 25.488 & & \\
\hline I believe I have the skills/technique to be successful in my sport & .80 & 21.591 & & \\
\hline I am confident in my abilities & .82 & 22.403 & & \\
\hline Dedication & & & .88 & .65 \\
\hline I am dedicated to achieving my goals in sport & .79 & 21.249 & & \\
\hline I am determined to achieve my goals in sport & .83 & 22.909 & & \\
\hline I am devoted to my sport & .78 & 20.724 & & \\
\hline I want to work hard to achieve my goals in sport & .83 & 22.669 & & \\
\hline Vigor & & & .83 & .55 \\
\hline I feel energized when I participate in my sport & .72 & 18.208 & & \\
\hline I feel energetic when I participate in my sport & .74 & 19.043 & & \\
\hline I feel really alive when I participate in my sport & .80 & 21.339 & & \\
\hline I feel mentally alert when I participate in my sport & .70 & 17.546 & & \\
\hline Enthusiasm & & & .84 & .57 \\
\hline I feel excited about my sport & .75 & 19.172 & & \\
\hline I am enthusiastic about my sport & .81 & 21.356 & & \\
\hline I enjoy my sport & .74 & 18.641 & & \\
\hline I have fun in my sport & .71 & 17.656 & & \\
\hline Intrinsic Motivation to Know & & & .82 & .53 \\
\hline $\begin{array}{l}\text { For the pleasure it gives me to know more about the sport that I } \\
\text { practice }\end{array}$ & .65 & 15.481 & & \\
\hline For the pleasure of discovering new training techniques & .66 & 15.964 & & \\
\hline $\begin{array}{l}\text { For the pleasure that I feel while learning training techniques that I } \\
\text { have never tried before }\end{array}$ & .76 & 19.261 & & \\
\hline For the pleasure of discovering new performance strategies & .83 & 23.443 & & \\
\hline
\end{tabular}


Table 2 (cont.)

Factor loadings, Z-values, construct reliability (CR), and average variance extracted (AVE)

\begin{tabular}{|c|c|c|c|c|}
\hline Constructs/items & $\begin{array}{l}\text { Factor } \\
\text { Loading }\end{array}$ & $\begin{array}{c}\mathrm{Z}- \\
\text { value }\end{array}$ & CR & AVE \\
\hline Intrinsic Motivation to Accomplish & & & .83 & .54 \\
\hline $\begin{array}{l}\text { Because I feel a lot of personal satisfaction while mastering certain } \\
\text { difficult training techniques }\end{array}$ & .72 & 17.470 & & \\
\hline For the pleasure I feel while improving some of my weak points & .70 & 15.810 & & \\
\hline For the satisfaction I experience while I am perfecting my abilities & .80 & 21.249 & & \\
\hline For the pleasure that I feel while executing certain difficult movements & .72 & 16.304 & & \\
\hline Intrinsic Motivation to experience stimulation & & & .77 & .53 \\
\hline For the excitement I feel when I am really involved in the activity & .75 & 18.005 & & \\
\hline For the intense emotions I feel doing a sport that I like & .67 & 15.831 & & \\
\hline Because I like the feeling of being totally immersed in the activity & .82 & 15.831 & & \\
\hline Extrinsic motivation - identified & & & .79 & .50 \\
\hline Because, in my opinion, it is one of the best ways to meet people & .69 & 13.276 & & \\
\hline $\begin{array}{l}\text { Because it is one of the best ways I have chosen to develop other aspects } \\
\text { of myself }\end{array}$ & .71 & 13.905 & & \\
\hline $\begin{array}{l}\text { Because it is one of the best ways to maintain good relationships with } \\
\text { my friends }\end{array}$ & .72 & 14.776 & & \\
\hline Extrinsic motivation - introjected & & & .78 & .50 \\
\hline $\begin{array}{l}\text { Because it is absolutely necessary to do sports if one wants to be in } \\
\text { shape }\end{array}$ & .71 & 14.358 & & \\
\hline Because I must do sports to feel good myself & .70 & 14.286 & & \\
\hline Because I must do sports regularly & .72 & 14.818 & & \\
\hline Extrinsic motivation - external regulation & & & .75 & .50 \\
\hline Because it allows me to be well regarded by people that I know & .68 & 17.886 & & \\
\hline Because people around me think it is important to be in shape & .65 & 17.490 & & \\
\hline To show others how good I am at my sport & .79 & 20.350 & & \\
\hline Amotivation & & & .82 & .53 \\
\hline $\begin{array}{l}\text { I used to have good reasons for doing sport, but now I am asking myself } \\
\text { if I should continue doing it }\end{array}$ & .68 & 16.350 & & \\
\hline $\begin{array}{l}\text { I don't know anymore; I have the impression of being incapable of } \\
\text { succeeding in this sport }\end{array}$ & .81 & 19.350 & & \\
\hline It is not clear to me anymore; I don't really think my place is in sport & .75 & 18.319 & & \\
\hline I often ask myself; I can't seem to achieve the goals that I set for myself & .67 & 16.871 & & \\
\hline Task Orientation & & & .80 & .50 \\
\hline I learn a new skill by trying hard & .66 & 15.506 & & \\
\hline I work really hard & .74 & 17.846 & & \\
\hline Something I learn makes me want to go and practice more & .73 & 17.376 & & \\
\hline I do my very best & .69 & 16.216 & & \\
\hline Ego Orientation & & & .81 & .52 \\
\hline I can do better than my friends & .65 & 14.770 & & \\
\hline The others can't do as well as me & .75 & 17.735 & & \\
\hline Others mess me up and I don't & .69 & 15.912 & & \\
\hline I'm the best & .78 & 18.671 & & \\
\hline
\end{tabular}



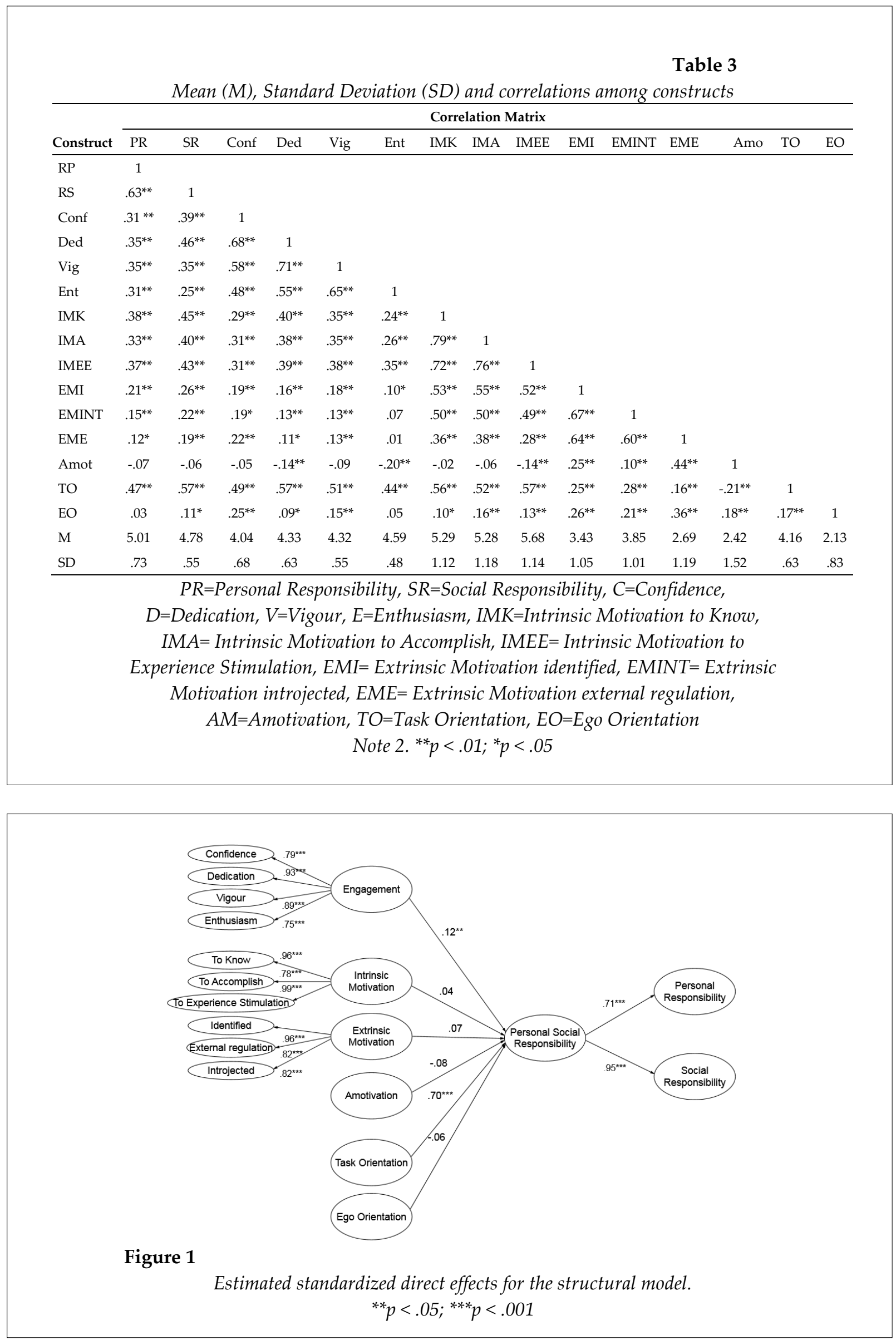
The CFI and TLI were within the .90 criterion for good fit, while RMSEA was less than .06, therefore also suggesting good fit (Hair et al., 2009). All estimated factor loadings exceed the cut-off point of .50 (Hair et al., 2009), ranging from .65 to .89 , while the Z-values ranged from 13.276 to 25.488 . These results indicate that each item did load significantly on its construct, and suggest that the items accurately captured their respective factors (Anderson and Gerbing, 1988). As shown in Table 1, the composite reliability coefficients for each latent factor supported the constructs reliability. Values ranged from .75 to .89 , thus exceeding the recommended minimum of .60 (Bagozzi and Kimmel, 1995). Convergent validity was accepted for all constructs, given that each construct's AVE values met accepted levels of .50 (Fornell and Larcker, 1981), ranging from .50 to .68 .

Descriptive statistics of the first-order constructs, as well as their correlations, are reported in Table 2. All correlation coefficients between constructs were lower than the suggested criterion of .85 (Kline, 2005), and most AVE values were greater than the squared correlations between all construct pairings. Therefore, discriminant validity was accepted (Fornell and Larcker, 1981). Based upon these results, scale items were deemed reliable for further analysis.

After confirming the appropriateness of the first-order model, the model including secondorder constructs was examined. The goodness-offit indices produced for the second-order measurement model indicated good fit to the data $\left[\chi^{2}(1854)=3635.61(p<.001), \chi^{2} / d f=1.99 ; C F I=.90\right.$; $\mathrm{TLI}=.89 ;$ RMSEA $=.046]$. The paths between the second-order factors and their proposed subscales were all significant at $p<.001$. Inspection of standardized coefficients indicated that both personal and social dimensions were significantly related with the second order construct of PSR (Figure 1). Similarly, dedication, vigor, confidence and enthusiasm were significantly related with the engagement construct. With respect to the intrinsic motivation construct, standardized coefficients shown in Figure 1 also indicated that intrinsic motivation to accomplish, intrinsic motivation to know, and intrinsic motivation to experience stimulation were significantly linked to the respective second-order construct. Finally, the extrinsic motivation construct was well represented by 'identified extrinsic motivation', 'external regulation of extrinsic motivation' and 'introjected extrinsic motivation' (Figure 1). Based on these results, the second-order measurement model was deemed appropriate for further analysis and, consequently, the structural model was examined.

\section{Analysis of the structural model}

The examination of the structural model included a test of the overall model fit as well as a test of the relationships between the latent constructs (Loehlin, 2003). The overall assessment of the structural model indicated an acceptable fit to the data $\left[\chi^{2}(1450)=3040.20(p<.001), \chi^{2} / d f=\right.$ 2.10; $\mathrm{CFI}=.89$, TLI $=.88$, RMSEA $=.05]$. Although the CFI and TLI values were below the recommended criterion for good fit (Hair et al., 2009), the ratio of the $\chi^{2}$ for its degrees of freedom was below the suggested 3.0 value, therefore indicating good fit. Also, the RMSEA was indicative of good fit (Hair et al., 2009; Mâroco, 2010). Inspection of the path coefficients (Figure 1) revealed that task orientation $(\beta=.70, p<.001)$ and engagement $(\beta=.12, p<.05)$ were significant positive predictors of personal and social responsibility (PSR). Intrinsic motivation $(\beta=.04$, $p>.05)$, extrinsic motivation $(\beta=.07, p>.05)$, amotivation $(\beta=-08, p>.05)$ and ego orientation $(\beta=-06, p>.05)$ were not significant predictors of PSR. Globally, these variables accounted for approximately $74 \%$ of the variance on PSR $\left(\mathrm{R}^{2}=\right.$ $.74)$.

\section{Discussion}

The main goal of this study was to assess the relationships between self-determination and achievement goal motivation, engagement, personal and social responsibility among athletes. In doing so, this study aimed to contribute to the body of literature by: (1) responding to the previously diagnosed lack of empirical studies concerning youth's positive development through sport within the research field, and (2) providing sport psychologists and other professionals with an instrument for their work with athletes, thus allowing the monitoring of motivation, engagement levels as well as personal and social responsibility (Hellison and Walsh, 2002).

There is a lack of empirical studies concerning the psychological antecedents of personal and social responsibility in order to serve as a 
foundation for our discussion. Notwithstanding, while attempting to determine the strategies used by teachers to improve personal and social responsibility, researchers found a positive association between personal and social responsibility and the learning of behaviors and attitudes that could promote responsibility (Escartí et al., 2010). This highlights the idea that there is a positive association between task orientation and the perception of sport that might contribute to PSR development in physical education (Lee et al., 2000). Also, Duda and Hall (2001) indicate that self-perceived environments associated with both task oriented goals and positive affective engagement provide a positive enhanced effect over youth behavior and development. Moreover, several studies have shown an improvement of youth's selfeffectiveness towards achieving both selfregulation and social competences (Escartí et al., 2013; Weidong et al., 2008).

Our results obtained through the structural model indicated that task orientation and engagement were positively correlated with personal and social responsibility. The results can contribute to strengthen the research field of positive youth development, and to clarify which dimensions of the motivational profile facilitate the improvement of personal and social responsibility. Thus, monitoring the type of motivational orientations might contribute to a better implementation of personal and social responsibility programs. Also, coaches and practitioners should regard sport engagement as a tool to promote positive youth development (Biddle and Mutrie, 2001).

While the literature suggests a negative relationship between ego orientation and positive social attitudes (Harwood et al., 2000), such a connection was not significant in this study. In the youth-related literature, however, the main concept regarding the development of responsibility revolves around maintaining a high task orientation, regardless of its combination with ego orientation (Gould and Carson, 2008). Consequently, since the primary goal of a taskorientated athlete is to either produce an adequate behavior or solve a problem for its own sake (rather than to demonstrate personal ability), the degree to which the athlete is ego oriented is not deemed to represent a positive or negative feature of the athlete (Maehr and Nicholls, 1980).

Finally, engagement was found to be strongly associated to personal and social responsibility. Engagement reflects the connection between a subject and the chosen activity (Hodge et al., 2009). Moreover, the choice to persevere in a sport is an outcome of cognition and affective responses that demonstrate personal and social responsibility. Given the significant association between such social skills in the proposed model, the results of this study might suggest that coaches should consider promoting engagement through PSR programs.

Furthermore, the results of this study showed that the levels of athlete self-determination had no significant relationship with personal and social responsibility levels. We did not find significant relationships between intrinsic motivation, extrinsic motivation as well as personal and social responsibility levels. These results may suggest that an athlete can adhere to positive social behaviors by conforming to the rules, even when disagreeing with them or failing to understand them, at least initially (Ryan et al., 1992). However, this study is an important step forward, due to the presentation of a model meant to provide a better understanding of PSR through sports, including the concurrent self-perception by athletes concerning motivation and engagement.

In summary, this study found a significant positive relationship between both task orientation and engagement constructs, and PSR. Therefore, an increased focus on task-oriented motivation and athlete engagement is, for sure, relevant to psychologists and coaches working on sport programs geared towards the development of social behaviors in youngsters.

From a theoretical point of view, these results might represent a key foundation for future studies, focused on understanding the development of personal and social responsibility in different sport settings. On the other hand, suggestions related to coaches's actions when implementing personal and social responsibility programs include, for example, activities being focused on learning and individual progress. Additionally, when the purpose of gaining competence or knowledge is the central concept, athletes must also be stimulated to do things well, in the sense of corresponding to the expectations 
of others concerning their role in society and sport. Coaches should also highlight that mistakes are part of the process of acquiring competence and knowledge, since it could result in enhancing athletes' perception of increased engagement. Promoting the feelings of confidence in one's ability to perform at a high level, focusing on how dedicated athletes are to sacrificing themselves to continue training hard, promoting the physical, mental, and emotional energy of the athletes, and enjoyment levels, may help to extend the sport career of the young athletes, which is a desirable goal in order to promote behavioral change (Martins et al., 2014).

Given the importance and practical relevance of the constructs concerning personal and social responsibility, this study provides useful clues in guiding the overall development and improvement of physical activity programs geared to promote positive youth development. This might be a valuable contribution to the body of literature on youth positive development through sport, which until now has been lacking in quantitative results.

\section{Limitations and future directions}

It is important to note that, as with any study, there are limitations that should be acknowledged, and therefore considered in future research. First, this study was based on a sample from a single country, which may limit the generalization of the resuls to sport settings in general. Thus, it is important to replicate the present factorial structure in future studies using samples of athletes from different cultural contexts. Given this, we propose combining different instruments and methodologies. As Weidong et al. (2008) posited, other assessment forms should be combined with the PSR scale (e.g., athlete's interviews, coach notes, diaries, and records), since doing so might be more reliable in assessing youth positive development through sport. We also recognize some additional research possibilities, noticing that research must be conducted within live intervention or training programs, so as to empirically investigate its effect on sport contexts. This will result in greater consistency of researchers' efforts to increase the understanding of how the development of personal and social responsibility is influenced by sport. On the other hand, despite the predictive efficacy of some proposed constructs on PSR, future research could investigate other potential antecedents of personal and social responsibility through sport. For example, PSR is determined by a number of factors and their interactions, including heredity, childhood experiences, modelling by significant adults, peer influences, physical and social environments, media, a variety of organizations (family, school, church, and others) and the specific situations and roles that each individual assumes in life (Phelps et al., 2009). Nevertheless, several programs have been recently designed with the intention of influencing the development of moral values, thus highlighting the potential contributions of sport in PSR education (Schilling, 2001). These experiences, related to physical activity, ensure the active and significantly effective implementation of values, which is a positive contribution within the process of youngsters' personal and social development (Hellison and Martineck, 2006; Martinek and Pérez, 2005). Additionally, the specific type and level of each athlete's sport involvement constitute a common form of participation that significantly influences youth development (Appleton et al., 2006). In this sense, examining the role of PSR within athletes of distinct competitive levels may prove to be vital for understanding how some are driven to compete with fair-play (i.e., concern with rules and the public's assessment of their behavior) (Martin, 2008). Such lines of research may provide useful insights in understanding the most influential variables within the long term process of sport participation and the development of responsibility levels.

\section{Acknowledgements}

This research was supported by a grant (SFRH/BD/45885/2008) from the Foundation for Science and Technology (FCT-Portugal). 


\section{References}

Anderson JC, Gerbing DW. Structural equation modelling in practice: A review and recommended two-step approach. Psychol Bull, 1988; 103: 411-423

Appleton J, Christenson S, Kim D, Reschly A. Measuring cognitive and psychological engagement: Validation of the Student Engagement Instrument. J School Psychol, 2006; 44: 427-445

Appleton JJ, Christenson SL, Furlong MJ. Student engagement with school: Critical conceptual and methodological issues of the construct. Psychol Schools, 2008; 45: 369-386

Bagozzi RP, Kimmel SK. A comparison of leading theories for the prediction of goal-directed behaviours. Brit J Soc Psychol, 1995; 34: 437-461

Biddle S, Mutrie N. Psychology of physical activity: Determinants, well-being, and interentions. New York: Routledge; 2001

Biddle S, Wang J, Kavussanu M, Spray C. Correlates of achievement goal orientations in physical activity: A systematic review of research. Eur J Sport Sci, 2003; 3: 1-20

Carbonneau N, Vallerand RJ, Lafreniere MA. Toward a tripartite model of intrinsic motivation. J Pers, 2012; 80(5): 1147-1178. doi: 10.1111/j.1467-6494.2011.00757

Catalano RF, Berglund ML, Ryan JA, Lonczak HS, Hawkins JD. Positive youth developmental in United States: Research findings on evaluations of positive youth developmental programs, 1999. Available at http://aspe.hhs.gov/hsp/PositiveYouthDev9; accessed on: 29.08.2015

Chi L, Duda J. Multi-sample confirmatory factor analysis of the Task and Ego Orientation in Sport Questionnaire. Res Exerc Sport, 1995; 66: 91-98

Danish S, Forneris T, Hodge K, Heke I. Enhancing Youth Development Through Sport. World Leis J, 2004; 46: $38-49$

Deci EL, Ryan RM. The "what" and "why" of goal pursuits: Human needs and the self-determination of behavior. Psychol Inq, 2000; 11: 227-268

Duda J, Hall H. Achivement goal theory in sport: recent extensions and future directions. In R. Singer, H. Hausenblas \& C. Janelle (Eds.), Handbook of Sport Psychology. New York: Wiley. 417-443; 2001

Duda JL, White SA. Goals and beliefs about success among elite skiers. Sport Psychol, 1992; 6, 334-343

Escartí A, Gutiérrez M, Pascual C, Llopis R. Implementation of the Personal and Social Responsibility Model to Improve Self-Efficacy during Physical Education Classes for Primary School Children. Int J Psychol Psychol Ther, 2010; 10(3): 387-402

Escartí A, Gutiérrez M, Pascual C, Wright P. Observation of the strategies that physical education teachers use to teach personal and social responsibility. Rev Psicol Deporte, 2013; 22: 159-166

Fonseca AM, Biddle S. Prelimary test for adaptation of the TEOSQ in a portuguese sport scenario (TEOSQp). In A. M. Fonseca (Ed.), A FCDEF-UP e a Psicologia do Desporto: Estudos sobre motivação. Porto, Portugal: Editora da Universidade do Porto; 2001

Fornell C, Larcker DF. Structural equation models with unobserved variables and measurement error: Algebra and statistics. J Mark Res, 1981; 18: 382-388

Gould D, Carson S. Life skills development through sport: current status and future directions. Int Rev Sport Exerc Psychol, 2008; 1: 58-78

Hair JF, Black WC, Babin B, Anderson RE. Multivariate data analyses (7th ed.). New York: Prentice Hall; 2009

Harwood CG, Hardy L, Swain A. Achievement goals in competive sport: A critique of conceptual and measurement issues. J Sport Exerc Psychol, 2000; 22: 235-255

Hellison D, Martineck T. Social and individual responsibility programs. In D. Kirk, D. Macdonald \& M. O'Sullivan (Eds.), The handbook of physical education. Thousand Oaks, CA: Sages Publications Ltd, 610626; 2006

Hellison D, Walsh D. Responsibility-based youth programs evaluation: Investigating the investigations. 
Quest, 2002; 54: 292-307

Hodge K, Lonsdale C, Jackson SA. Athlete Engagement in Elite Sport: An Exploratory Investigation of Antecedents and Consequences. The Sport Psychologist, 2009; 23: 186-202

Klem AM, Connell JP. Relationships matter: Linking teacher support to student engagement and achievement. J School Health, 2004; 74: 262- 273

Kline RB. Principles and practice of structural equation modelling. New York: The Guilford Press; 2005

Lee M, Whitehead J, Balchin N. The measurement of values in youth sport: development of the youth sport values questionnaire. J Sport Exerc Psychol, 2000; 22: 307-326

Lerner RM. Promoting positive development in adolescence through sports and other youth programs: Implications of the 4-H Study of Positive Youth Development. J Sport Exerc Psychol, 2009; 31: S3-S3

Li W, Wright PM, Rukavina PB, Pickering M. Measuring Students' Perceptions of Personal and Social Responsibility and the Relationship to Intrinsic Motivation in Urban Physical Education. J Teach Physl Educ, 2008; 27: 167-178

Loehlin JC. Latent variable models: An introduction to factor, path, and structural equation analysis (4th ed.). Mahwah, NJ: Lawrence Erlbaum Associates; 2003

Lonsdale C, Hodge K, Jackson SA. Athlete engagement: II. Development and initial validation of the Athlete Engagement Questionnaire. Int J Sport Psychol, 2007; 38: 471-492

Lonsdale C, Hodge K, Raedeke TD. Athlete engagement: I. A qualitative investigation of relevance and dimensions. Int J Sport Psychol, 2007; 38: 451-470

Maehr ML, Nicholls JG. Culture and achievement motivation: A second look. In N. Warren (Ed.), Studies in cross cultural psychology, New York: Academic Press, 221-267; 1980

Marôco J. Structural equations analysis: theoretical foundations, software \& applications. Lisboa: Report Number; 2010

Martin AJ. Motivation and engagement in music and sport: Testing a multidimensional framework in diverse performance settings. J Pers, 2008; 76(1): 135-70

Martinek T, Pérez LMR. Promoting positive youth development through a values-based sport program. Int J Sports Sci, 2005; 1(1): 1-13

Martins P, Rosado A, Ferreira V, Biscaia R. Examining the validity of the Athlete Engagement Questionnaire (AEQ) in a Portuguese sport setting. Motriz: J Phys Ed, 2014; 20: 1-7

Martins P, Rosado A, Ferreira V, Biscaia R. Examining the Validity of the Personal-social Responsibility Questionnaire among Athletes. Motriz: J Phy. E., 2015; 23: 321-328

Nicholls JG. The competitive ethos and democratic education. Cambridge, MA: Harvard University Press; 1989

Pelletier LG, Tuson KM, Fortier MS, Vallerand RJ, Briere NM, Blais MR. Toward a New Measure of Intrinsic Motivation, Extrinsic Motivation, and Amotivation in Sports - the Sport Motivation Scale (Sms). J Sport Exerc Psychol, 1995; 17: 35-53

Phelps E, Zimmerman S, Warren AEA, Jelicic, von Eye A, Lerner RM. The structure and developmental course of Positive Youth Development (PYD) in early adolescence: Implications for theory and practice. J Appl Dev Psychol, 2009; 30: 571-584

Ryan RM, Connell JP, Grolnick WS. When achievement is not intrinsically motivated: A theory of internalization and self-regulation in school. In A. K. Boggiano \& T. S. Pittman (Eds.), Achievement and motivation: A social development perspective. Cambridge: Cambridge University Press, 167-188; 1992

Ryan RM, Deci EL. Self-determination theory and the facilitation of intrinsic motivation, social development, and wellbeing. Am Psychol, 2000; 55: 68-78

Russell VJ, Ainley M, Frydenberg E. Schooling issues digest: Student motivation and engagement, 2005. Available at: http://www.dest.gov.au/sectors/school education/publications resources/schooling issues digest/schooling issues digest motivation engagement.htm; accessed on 01.08.2015 
Schilling TA. An investigation of commitment among participants in an extended day physical activity program. Research Quarterly for Exercise and Sport, 2001; 72: 355-366

Serpa S, Alves P, Barreiros A. Portuguese version of the Sport Motivational Scale (SMSp): translation, adaptation and reliability processes. Lisboa: Faculdade de Motricidade Humana - Universidade Técnica de Lisboa; 2004

Vallerand RJ, Fortier MS, Guay, FDR. Self-determination and persistence in a real-life setting: Toward a motivational model of high school dropout. J Pers Soc Psychol, 1997; 72: 1161-1176

Vallerand RJ, Thill EE. Introduction to the concept of motivation. In R. J. Vallerand \& E. E. Thill (eds.), Introduction to the psychology of motivation. Laval, Canada: Éditions Études Vivantes, 3-39; 1993

Ward S, Parker M. The voice of youth: atmosphere in positive youth development program. Phys Educ Sport Pedag, 2013; 18(5): 534-48

Watson D, Newton M, Kim M. Recognition of values-based constructs in a summer physical activity program. Urban Review, 2003; 35: 217-32

Weidong L, Wright P, Rukavina P, Peckering M. (2008). Measuring Students Perceptions of Personal and Social Responsibility and Relationship to Intrinsic Motivation in Urban Physical Education. J Teach Phys Educ, 2008; 27: 167-178

Wright PM, Craig MW. Tool for Assessing Responsibility-Based Education (TARE): Instrument Development, Content Validity, and Inter-Rater Reliability. Meas Phys Educ Exerc Sci, 2011; 15: 204-219

Wright PM, Li W. Exploring the relevance of a youth development orientation in urban physical education. Phys Educ Sport Pedag, 2009; 14: 241-251

\section{Corresponding author:}

\section{Paulo Martins}

Faculdade de Motricidade Humana, Universidade de Lisboa

Estrada da Costa

1499-002 Cruz Quebrada - Dafundo - Portugal

Email: pmartins@fmh.ulisboa.pt

Telephone: +351 214149175 